\title{
Joan AMENÓS ÁLAMO, El mito legal de la ciudad compacta, Servicio de Publicaciones de la UAB, Barcelona, diciembre de 2015
}

\author{
Joan AMENÓS ÁLAMO, The legal myth of compact cities, UAB \\ Publishing Services, Barcelona, December 2015
}

Oriol Caudevilla Parellada

Universidad Autónoma de Barcelona oriolcaudevilla@icab.es

\section{RESUMEN}

Así como en EE.UU se produjo un claro desarrollo de la urbanización dispersa muchas décadas atrás, en España este fenómeno era relativamente desconocido hasta los últimos treinta años, cuando sí hemos empezado a imitar en cierto modo el proceso de descentralización americano y han empezado a surgir urbanizaciones alejadas del centro de las ciudades. Como consecuencia de ello, se han creado en España instrumentos jurídicos concretos que se utilizan para lograr el objetivo de la compacidad, creándose en cierto modo el mito legal de la ciudad compacta.

Ahora bien, aunque la ciudad compacta pueda ser un modelo positivo, resulta discutible que el legislador intente imponer este modelo ya que, en ocasiones, la sobrecarga reguladora no sólo no acaba con la dispersión, sino que la estimula directa o indirectamente, multiplicando además los precios de forma artificial.

\section{Palabras clave}

Urbanización dispersa, ciudad compacta, desarrollo sostenible.

\begin{abstract}
In the same way that in the USA a clear case of suburban sprawl took place many decades ago, this phenomenon remained relatively unknown in Spain until thirty years ago, when this process began to be imitated here. Because of all this, many legal instruments have been created in Spain, instruments whose target is precisely to make Spanish cities more compact, therefore creating in some way the legal myth of the compact city.

However, even if the compact city may be a positive model, the fact that the lawmaker tries to impose that model may be discussed, as, sometimes, an overload of regulations may not only fail to finish with the sprawl, but may stimulate this phenomenon, directly or indirectly. Moreover, it may artificially increase home prices.
\end{abstract}

\section{Keywords}

Sprawl, compact cities, sustainable development. 
Reseña de Joan AMENÓS ÁLAMO, El mito legal de la ciudad compacta, Servicio de Publicaciones de la UAB, Barcelona, diciembre de 2015.

El libro El mito legal de la ciudad compacta, escrito por Joan Amenós Álamo ${ }^{1}$, acaba de ser publicado en diciembre de 2015 por el Servicio de Publicaciones de la UAB, siendo una de las primeras y pocas obras editadas en español en las que se aborda el estudio del urbanismo desde una perspectiva comparada. El prólogo ha sido escrito por Robert Bruegmann², autor de Sprawl. A compact history (traducida al español como La dispersión urbana. Una historia condensada). El libro de Bruegmann sin duda ha inspirado al autor a la hora de realizar el estudio y la comparación (de hecho, Joan Amenós es un gran admirador de Sprawl, tal y como nos lo demuestra el hecho de que publicó en REALA una reseña a la traducción en español de la obra en el núm. 1 de la nueva época de la revista).

Considero que se trata de una obra especialmente interesante en la medida que, si bien el autor se centra en analizar el urbanismo español, lo hace partiendo de la comparación con el urbanismo de los Estados Unidos de América, y además lo hace desde una perspectiva multidisciplinar. Es cierto que se trata de un libro jurídico, pero se ha concebido con la finalidad de llegar a un público más general, de tal modo que puede ser leída y comprendida por personas procedentes de otros ámbitos del conocimiento (arquitectura, geografía, ciencias políticas, historia del arte...), por lo que el espíritu interdisciplinar está claramente presente en ella.

La tesis o idea de partida del autor es simple: analiza dos fenómenos contrapuestos como son la ciudad compacta y la urbanización descentralizada (calificada a veces por los especialistas anglosajones como "ciudad difusa», sprawl). Así como en EE.UU se produjo un claro proceso de urbanización dispersa, muchas décadas atrás, en España este fenómeno era relativamente desconocido hasta los últimos treinta años. No obstante, fue a partir de la década de los ochenta cuando en España empezamos a imitar el proceso de descentralización americano, comenzando a surgir urbanizaciones dispersas alejadas del centro de las ciudades. El autor intenta evitar los juicios de valor: si bien muchos autores demonizan el concepto de ciudad dispersa, Joan Amenós intenta en todo momento valorar los pros y contras de cada tipología de ciudad, sin imponer un modelo $u$ otro.

La obra se divide en tres partes: en la primera, el autor expone reflexiones sobre la evolución de la

1 Profesor Titular de Derecho Administrativo de la Universidad Autónoma de Barcelona (UAB).

2 Catedrático emérito de Historia del Arte, Arquitectura y Planificación Urbana de la Universidad de Illinois (Chicago). dispersión urbana en los últimos decenios, refiriéndose sobre todo al ejemplo norteamericano como paradigma de lo que posteriormente ocurrió en Europa. En la segunda, se centra ya en cuestiones más jurídicas, exponiendo cómo la mayoría de la doctrina ha criticado la importación de este fenómeno típicamente americano y ha intentado frenarlo. Finalmente, en la tercera parte, se expone un listado que recoge las principales medidas normativas contra la dispersión urbana.

En relación a la evolución de la dispersión urbana, debemos tener en cuenta que, si bien es un fenómeno que ha alcanzado su máxima expresión en los EE.UU ${ }^{3}$, no es menos cierto que, hoy en día, en los EE.UU se está replanteando el retorno gradual a un modelo de ciudad compacta, el fenómeno conocido como «back to the city».

Esta situación de dispersión es consecuencia de la ruptura del tejido urbano tradicional, que se produjo en la segunda mitad del siglo XX en las grandes urbes estadounidenses: aquellas ciudades que antaño presentaban una intensa vitalidad económica, cambiaron. Tuvo lugar una rápida expansión de la urbanización difuminada, expansión que, si bien se empezó a gestar ya en los años veinte del siglo pasado, alcanzó su apogeo en la década de los cincuenta, hasta el punto de que en 1970 vivía más población en los suburbs que en la suma global de las ciudades y las áreas rurales acumuladas.

Este fenómeno tan sencillo de explicar en unas pocas líneas tiene unas implicaciones muy grandes, acarreando notables consecuencias: si las ciudades, los downtown, pierden habitantes, ello implicará que éstas pierdan comercio y que los habitantes de clase media-alta ya no quieran seguir viviendo en pisos o apartamentos pequeños en áreas venidas a menos, sino que querrán (así fue en la realidad) mudarse a los suburbs, a las afueras, donde podrán disponer de casas unifamiliares mucho más grandes (con todas las implicaciones que ello conlleva, a nivel de necesidades de infraestructuras, entre otras muchas).

Ahora bien, si existen movimientos como el New Urbanism que han criticado este fenómeno, ha habido autores como Bruegmann (pocos, no obstante) que han opinado que la dispersión urbana no es un problema ni una desgracia que debe corregirse implacablemente a través de una contundente planificación administrativa. En esta línea se ha orientado el Derecho Urbanístico español más reciente, como veremos.

3 Tal y como nos indica el autor, «Una urbanización de prósperas clases medias con viviendas unifamiliares aisladas o adosadas se asocia normalmente con el modo de poblamiento favorito en los Estados Unidos» (pág. 27). 
Joan Amenós no se limita a analizar el fenómeno de la dispersión urbana solamente en EE.UU, sino que estudia algunos ejemplos más próximos, como el de la región metropolitana de Barcelona, caso que analiza ampliamente. En este punto, Amenós cita a Bruegmann cuando indica que «la urdimbre de baja densidad constituida por autopistas, urbanizaciones y parques industriales y de oficinas en la periferia de Bolonia o Barcelona tiene un mayor parecido con las afueras de las ciudades americanas que con las del norte de Europa» ${ }^{4}$.

Centrándonos en la segunda parte de la obra, debemos destacar que, en ella, el autor analiza la recepción legal del concepto que bautiza como el «mito legal de la ciudad compacta». Lo hace reconociendo que la doctrina jurídico-urbanística española, normalmente, ha rehuido las discusiones sobre los patrones de organización urbana pero, cuando han entrado en ellas, en general han admitido con desagrado el triunfo de la ciudad dispersa, mostrando siempre mayoritariamente su preferencia por la ciudad compacta. Hasta el punto de que el autor llega a identificar al final del capítulo de forma clara el nacimiento del mito, puesto que «todos los mitos tienen su rito de nacimiento» (pág. 76): la fe en la ciudad compacta, si bien anteriormente asumida ya por algunas Comunidades Autónomas, nació sobre todo a partir de la Ley 8/2007, de suelo, y en especial en su Exposición de Motivos, cuya redacción sería recogida íntegramente en el Texto refundido de la Ley sobre el Régimen del Suelo y Ordenación Urbana de 2008. En dicho preámbulo se avisa que se quería establecer una reacción contra la «historia desarrollista» del urbanismo español contemporáneo, "volcada sobre todo en la creación de nueva ciudad». Se considera que "el crecimiento urbano sigue siendo necesario», si bien se considera que «el urbanismo debe responder a los requerimientos de un desarrollo sostenible».

Este «urbanismo sostenible» se materializa apostando por que el impacto del crecimiento urbano debe ser minimizado y por la preferencia por "un modelo de ciudad compacta» de acuerdo con la insistencia de la Unión Europea (por ejemplo, en la Estrategia Territorial Europea).

El autor termina el capítulo considerando que "es verdad que lo compacto suele alinearse últimamente con una visión más "progresista" o discretamente socializante, mientras que la desparramada urbe metropolitana se identificaría con "la nueva ciudad capitalista"» (pág. 82). No obstante, el propio autor nos recuerda que esta distinción no parece del todo acertada, ya que muchas urbanizaciones de baja densidad pueden presentar un carácter

4 BRUEGMANN, Robert (2005): 75-76. «popular» al haber sido erigidas como respuesta a los elevados precios de la cara urbe central.

Ya en el tercer capítulo, el autor analiza los instrumentos jurídicos concretos que se utilizan para lograr el objetivo de la compacidad. Porque, a estas alturas de la obra, el lector tiene ya claro que, en España, el objetivo del legislador en los últimos años ha sido precisamente garantizar la compacidad de la ciudad. Y lo ha hecho a través de una gran cantidad de herramientas jurídicas, ya sean normas, medidas y decisiones tomadas en el seno de múltiples estrategias sectoriales. Podemos destacar, como herramientas significativas, tanto el vigente principio de contención de la urbanización (derivado del art. 20.1.a) de la LSRU ${ }^{5}$ ) como la exigencia de una densidad mínima preceptiva (exigencia derivada de la aprobación de normas con rango de ley que fijan densidades mínimas obligatorias, verbigracia el art. 22.1 de la Ley $2 / 2006$, de 30 de junio, de Suelo y Urbanismo del País Vasco).

Sobre la densidad mínima preceptiva, considero necesario remarcar que la determinación de la densidad de población y de viviendas previstas para un determinado ámbito ha constituido uno de los contenidos tradicionales de los planes de urbanismo. La novedad radica en la fijación legal de estas densidades mínimas obligatorias, tal y como vimos en el párrafo anterior. Ello implica, por un lado, la sobrecarga de la ley, al acoger en su seno materias que anteriormente eran propias de planes con rango de reglamento y, por otro lado, la constatación el triunfo de las teorías favorables a la ciudad compacta, al poder exigir una ley una densidad mínima que los planificadores no podrán rebajar (que es precisamente lo que se hace en el art. 22.1 de la Ley 2/2006 del País Vasco antes mentado).

De todos modos, no tendría sentido en esta reseña resumir las casi sesenta páginas que el autor dedica a analizar los múltiples instrumentos jurídicos urbanísticos cuya finalidad última es precisamente la que acabamos de comentar, garantizar la compacidad de la ciudad y evitar su dispersión, como respuesta al supuesto fenómeno de dispersión urbanística que tuvo lugar en España entre 1980 y 2010.

En este sentido, creo necesario destacar, además, la relación que el autor establece entre los planes urbanísticos y la estructura comercial y económica de las ciudades. Uno de los instrumentos más estimados por los defensores de la ciudad compacta es, precisamente, la normativa específica que impide el nacimiento de nuevas áreas comerciales fuera del área urbana, es decir,

5 Real Decreto Legislativo 7/2015, de 30 de octubre, por el que se aprueba el texto refundido de la Ley de Suelo y Rehabilitación Urbana. 
la legislación específica contra la actividad comercial difusa. Dentro de este ámbito, podríamos incluir normas tales como la Ley estatal 7/1996, de 15 de enero, de Ordenación del Comercio Minorista y la Ley catalana 18/2005, de 27 de diciembre, de Equipamientos Comerciales, algunas de cuyas disposiciones fueron declaradas incompatibles con el art. 49 del Tratado de Funcionamiento de la Unión Europea en la Sentencia del Tribunal de Justicia de la Unión Europea de 24 de marzo de $2011^{6}$. Este tema, de gran actualidad, ha terminado siendo en muchos momentos un debate tanto jurídico como político relativo a qué modelo comercial tenemos y a qué modelo comercial queremos aspirar en el futuro. De hecho, ya tradicionalmente, los planes urbanísticos han incidido en el comercio, afectando la estructura mercantil de las ciudades.

Estas herramientas comerciales a las que se hace referencia han sido desarrolladas en España por la legislación de diversas Comunidades Autónomas, con gran protagonismo de Cataluña, siendo la principal institución utilizada la de la licencia comercial específica para la apertura de determinados negocios de elevada capacidad. Según el autor, "el discurso político y académico de la ciudad compacta puede utilizar perfectamente tales agarraderos legales y, de esta manera, asegurar en la realidad física la consagración del mito preconcebido» (pág. 151).

Una vez expuestos los tres capítulos, el autor se centra ya en las reflexiones finales, en las cuales nos recuerda cuál ha sido la evolución del proceso de dispersión urbana y nos indica su opinión al respecto. Considera que es dudoso que la Administración pública deba revertir y manipular estas tendencias, que en muchas ocasiones nacen de la iniciativa individual: la sobrecarga reguladora no va acabar con la dispersión.

Resulta importante remarcar que el autor no adopta en ningún momento una posición favorable o desfavorable ni hacia la ciudad dispersa ni hacia la ciudad compacta, sino que analiza las ventajas e inconvenientes de cada modelo. Aquello que el autor critica no es el concepto y modelo de ciudad compacta per se, sino el mito legal que se ha creado a su alrededor. Que la ciudad compacta pueda ser un modelo positivo no lo discute el autor, pero discute y rebate que el legislador intente imponer ese modelo que ha mitificado porque, tal y como nos recuerda, en ocasiones la sobrecarga regula-

\footnotetext{
6 Ahora bien, aunque el fallo TJUE fue claramente favorable a la libertad de comercio, no podemos dejar de lado que el Tribunal admitió que las razones ambientales y urbanísticas pueden limitar o restringir la instalación de nuevos equipamientos comerciales, abriéndole la puerta al legislador español para volver a las antiguas políticas restrictivas.
}

dora no sólo no acaba con la dispersión, sino que la estimula directa o indirectamente, multiplicando además los precios de forma artificial.

Probablemente, éste es el único punto que considero que podría mejorarse en el libro de Amenós: al no adoptar el autor una posición favorable o desfavorable hacia ninguno de los dos modelos, el análisis parece quedarse corto. Corto porque vemos claramente que el autor domina la materia, y vemos también que el autor debe tener claro por qué modelo apuesta, quedándonos con la sensación de que podría haber añadido un Capítulo IV en el cual optara finalmente por uno de los dos modelos, so riesgo de subjetivar en demasía su estudio.

El estilo de Amenós a la hora de redactar es claro y conciso, pero sin dejar en ningún momento de lado el rigor necesario en una obra de estas características, y a la vez literario (el autor demuestra ser un gran escritor, porque no sólo transmite correctamente la información, sino que lo hace con un estilo elegante y eficaz).

Como conclusiones personales a la obra, una vez realizado el análisis de los aspectos principales del libro, debo concluir esta recensión recordando lo que dije anteriormente: poco se ha estudiado el urbanismo español desde una perspectiva comparada, salvo algunas obras (LORA-TAMAYO) ${ }^{7}$.

Es precisamente por esta razón por la cual la presente obra resulta de mayor interés, porque no se limita a exponer la situación jurídica en España, sino que nos indica de dónde procede el modelo de ciudad compacta y nos permite ver que, muy probablemente, la opción más sabia que el legislador podría adoptar es entender que la dispersión urbana es un proceso por el que todo país avanzado debe pasar pero que, al final, es probable que se termine produciendo el fenómeno del «back to the city», sin necesidad de la adopción de una ingente cantidad de regulaciones (se trata de la denominada hipótesis de la circularidad).

\section{BIBLIOGRAFÍA}

AMENÓS ÁlAMO, Joan (2015): El mito legal de la ciudad compacta, Barcelona, Servicio de Publicaciones de la UAB.

BRUEGMANN, Robert (2005): Sprawl. A compact history, Chicago, The University of Chicago Press.

LORA-TAMAYO VALLVÉ, Marta (2002): Urbanismo de obra pública y derecho a urbanizar. Análisis comparado desde las aportaciones de G.E. Haussmann y la doctrina de Ildefonso Cerdá, Madrid, Marcial Pons.

7 LORA-TAMAYO VALLVÉ, Marta (2002). 